\title{
An 18 year data-linkage study on the association between air pollution and acute limb ischaemia
}

\author{
Catherine A. Fitton ${ }^{1}$, Bianca Cox², James D. Chalmers ${ }^{1}$, and Jill J. F. Belch ${ }^{1}$ \\ 1 University of Dundee NHS Tayside, Ninewells Hospital and Medical School, Dundee, UK \\ ${ }^{2}$ Centre for Environmental Sciences, Hasselt University, Diepenbeek, Belgium
}

\begin{abstract}
Summary: Background: There is limited information regarding the effects of air pollutants, such as nitrogen oxides ( $\left.\mathrm{NO}_{x}\right)$, nitric oxide $\left(\mathrm{NO}_{2}\right)$, nitrous oxide (NO) and particulate matter with a diameter smaller than $10 \mu \mathrm{m}$ (PM10), on acute limb ischaemia (ALI), a peripheral arterial disease (PAD) often with a poor clinical outcome. Patients and methods: We conducted an 18-year retrospective cohort study using routinely collected healthcare records from Ninewells Hospital, Dundee, and Perth Royal Infirmary, in Tayside, Scotland, UK from 2000 to 2017. ALI hospitalisation events and deaths were linked to daily $\mathrm{NO}_{\mathrm{x}}$ $\mathrm{NO}_{2}$, NO and PM10 levels extracted from publicly available data over this same time period. Distributed lag models were used to estimate risk ratios for ALI hospitalisation and for ALI mortality, adjusting for temperature, humidity, day of the week, month and public holiday. Results: 5,608 hospital admissions in 2,697 patients were identified over the study period (mean age 71.2 years, \pm 11.1$)$. $\mathrm{NO}_{\mathrm{x}}$ and $\mathrm{NO}$ were associated with an increase of ALI hospital admissions on days of exposure to pollutant ( $p=.018$ ), while PM10 was associated with a cumulative (lag 0-9 days) increase ( $p=.027)$ of ALI hospital admissions in our study. There was no increase of ALI mortality associated with pollution levels. Conclusions: ALI hospital admissions were positively associated with ambient $\mathrm{NO}_{x}$ and $\mathrm{NO}$ on day of high measured pollution levels and a cumulative effect was seen with PM10.
\end{abstract}

Keywords: acute limb ischaemia, pollution, hospital admissions, death

\section{Introduction}

Globally, 8.8 million deaths and 85 million disability adjusted life years (DALYs) a year are associated with air pollution [1]. While pollution related illnesses are often linked with middle- and low-income countries, pollution remains an important factor in developed countries, with around 40,000 deaths/annum in the UK [2]. Air pollution has been linked to a range of conditions [3], such as: cancer, asthma, exacerbations of bronchiectasis, stroke, heart disease, diabetes, and dementia.

Currently, limits on air pollution in Scotland are set by the Scottish government, using the World Health Organization's (WHO) air quality guidelines [1]. While the WHO documents give so-called "safe levels", it is recognised that they are unlikely to be entirely safe for the whole population [4]. In Scotland, limits of $40 \mu \mathrm{g} / \mathrm{m}^{3}$ for nitrogen dioxide $\left(\mathrm{NO}_{2}\right)$, $30 \mu \mathrm{g} / \mathrm{m}^{3}$ for nitrogen oxide (NO) and $18 \mu \mathrm{g} / \mathrm{m}^{3}$ for particulate matter with a diameter smaller than $10 \mu \mathrm{m}$ (PM10), have been set, and low emission zones have been introduced to larger cities in an effort to decrease air pollution from traffic. Despite this, air pollution is frequently not appreciated by Councils, particularly in semi-rural towns where it is seen as a "big city" problem, and pollution limits are not enforced.

Acute limb ischaemia (ALI) is defined as a sudden decrease in lower limb perfusion [5] which can lead to extensive tissue necrosis unless treated urgently [6]. ALI affects 1-1.5 individuals per 10,000 per year [7], and causes can be broadly split into two groups: embolism and thrombosis, excluding trauma [5]. Air pollution has been linked previously with embolism $[8,9]$ and thrombosis $[9,10]$ in other arterial regions. Air pollution is thought to induce inflammation [11], which triggers ischaemic damage by arteriosclerosis or thrombosis [12, 13, 14, 15]. There is no literature regarding the effects of air pollution on the incidence of ALI, a disease which can have serious consequences for the patient, such as amputation and significant disability.

This study, from the Tayside Pollution Research Programme (TPRP), aimed to investigate the association of air pollution on ALI hospital admissions and deaths over an 18-year period, across Tayside, a semi-rural area of Scotland, containing two of Scotland's smaller cities: 
Dundee (population circa 148,270) and Perth (population circa 44,820).

\section{Materials and methods}

This is a time series cohort study using data linkage. Exposure variable is pollutant $\left(\mathrm{NO}_{\mathrm{x}}, \mathrm{NO}_{2}, \mathrm{NO}, \mathrm{PM} 10\right)$. Confounding variables are temperature, humidity, day of week, public holiday, month and year. Outcome variable is ALI admission

Consent for the study was given by the Tayside Caldicott Guardian. Ethics approval and patient consent were not required as this data linkage study did not include patient participation. All data storage and analyses were carried out on anonymised data, held within the Safe Haven, the Tayside Health Informatics Centre (HIC). Hospital data is available from HIC with appropriate permissions. Pollution data is publicly available from: https://uk-air.defra.gov.uk/ data/data_selector.

\section{Patient population and patient data linkage}

This manuscript describes a record linkage study of hospital admissions at Ninewells Hospital, Dundee, UK and Perth Royal Infirmary, Perth, UK, from January 1st 2000 to December 31st 2017. These two hospitals are the catchment hospitals for ALI patients. Unique personal identifier codes (CHI) were used to extract electronic medical records from the Scottish Morbidity record 01 (SMR01) database that documents all hospitalization events in Scotland. Deaths were extracted from the National Records of Scotland (NRS) database.

\section{Hospital admission and death definition}

Hospital admissions and deaths of interest were agreed a priori and were defined by ICD10 code (2016 addition) recorded on the SMR01 or NRS records. Hospital admission for ALI or cause of death as ALI was defined as an IDC10 code of: I739: peripheral vascular disease, unspecified; I74: arterial embolism and thrombosis; or I702: atherosclerosis of arteries of extremities (full list of codes can be viewed in electronic supplementary material [ESM] 1). Only those with the appropriate ICD10 codes listed as a primary reason for hospital admission or death were included. Our vascular surgeons were consulted and confirmed that these ICD10 codes are used to capture "new onset acute limb ischemia within previous 2448 hours with no past history of chronic critical limb ischemia". Hospital admissions and deaths were restricted to patients over 45 and were aggregated to provide daily total ALI admissions and death. Admissions were also restricted to only those who reside in Dundee and Perth, in the following postcode districts: DD1, DD2, DD3, DD4, DD5, DD6, DD7, PH1 and PH2.

\section{Pollution data}

Pollution information is measured daily at urban background sites, throughout the UK, as part of the UK's Automatic Urban and Rural Network (AURN). Daily $\mathrm{NO}_{\mathrm{x}}, \mathrm{NO}_{2}$, $\mathrm{NO}$ and PM10 concentrations measured in Dundee and Perth were used for the analysis. Pollution data from Seagate was used for Dundee, while Atholl street was used for Perth. Data on mean air temperature and relative humidity were obtained from the UK Meteorological Office. Temperature and humidity data from Dalwhinnie were used for Perth, while temperature data from Mylnefield, near Dundee and humidity data from Leuchars, Fife was used for Dundee.

Supplemental figures 2, 3, 4 (ESM 2, 3, 4) show the measurement stations and postcode areas used. As pollution levels showed similar patterns and levels of pollution in each city, pollution levels were combined, and a daily average calculated and used for the analysis.

Where $<23$ data points were missing over a day, the rest of the points were averaged for the day. Where all data points were missing for the day, the day was excluded. The total number of excluded days was 4 .

\section{Statistical analysis}

To account for delayed effects of air pollution on ALI admissions, we combined quasi-Poisson regression with distributed lag (non-linear) models (DL(N)M) [16, 17], using separate models for PM10, $\mathrm{NO}_{\mathrm{x}}, \mathrm{NO}_{2}$ and NO. DL(N)Ms enable the investigation of the temporal pattern of the association, providing an estimate of the "overall" effect of the high measured pollution levels, incorporating potential delayed and harvesting effects. A DL(N)M model is defined through a "cross-basis" function, a bi-dimensional space of functions describing simultaneously the shape of the relationship along the space of the predictor (exposure-response function), and its distributed lag effects (lag-response function). We used a linear exposure-response function for the association between air pollution exposure and hospital admissions/deaths. The number of days included in the cross-basis was chosen based on visual inspection of the 3D exposure-lag-response surfaces. As exposure-response curves of all pollutants were relatively flat (i.e. risk ratios close to one) nine days after the high measured pollution levels, an extended lag period of 0-9 days (day of exposure up to 9 days after) was used. The lag structure was modelled with a natural cubic spline with two degrees of freedom (df), placing the knots at equally spaced values on the log scale of lags to allow more flexible lag effects at shorter delays [18]. Categorical variables for day of the week (1-7), month (1-12) and public holidays ( 0 or 1$)$ were included in the model to control for any weekly or monthly patterns in ALI admission. To account for the (potentially delayed) effects of meteorological factors on ALI admissions [19], we also included DLNM cross-bases for mean temperature and for humidity in the model. In both cross-bases, the maximum lag was set to 14 days and natural cubic splines with 
Table I. Pollution levels in Dundee and Perth over the study period

\begin{tabular}{|c|c|c|c|c|c|c|c|c|c|c|c|c|c|c|c|}
\hline & \multicolumn{5}{|c|}{ All data } & \multicolumn{5}{|c|}{ Dundee } & \multicolumn{5}{|c|}{ Perth } \\
\hline & Min & P25 & Median & P75 & Max & Min & P25 & Median & P75 & Max & Min & P25 & Median & P75 & Max \\
\hline $\mathrm{NO}_{x}$ & 16.1 & 109.0 & 146.0 & 190.0 & 570.0 & 11.3 & 120.4 & 165.0 & 210.4 & 713.0 & 18.1 & 94.5 & 134.0 & 182.0 & 615.0 \\
\hline $\mathrm{NO}_{2}$ & 9.3 & 41.2 & 51.1 & 61.7 & 118.0 & 7.8 & 39.5 & 49.7 & 56.0 & 150.0 & 0.0 & 39.4 & 52.0 & 64.1 & 136.0 \\
\hline NO & 4.5 & 44.2 & 61.8 & 84.7 & 294.0 & 1.7 & 51.9 & 75.0 & 98.2 & 367.0 & 5.4 & 34.9 & 52.9 & 76.9 & 323.0 \\
\hline PM10 & 2.9 & 12.5 & 16.8 & 22.8 & 89.5 & 1.0 & 9.2 & 13.4 & 19.5 & 93.6 & 1.0 & 15.8 & 21.0 & 27.5 & 105.0 \\
\hline
\end{tabular}

Mean and median for the whole study period, and for 2017 only, and highest/lowest quartiles are given. Pollution is measured as $\mu g / \mathrm{m}^{3}$. $\mathrm{NO}_{\mathrm{x}}$ : nitrogen oxides; $\mathrm{NO}_{2}$ : nitric oxide; NO: nitrous oxide; PM10: particulate matter with a diameter smaller than $10 \mu \mathrm{m}$.

five $\mathrm{df}$ were used to model the exposure-response and the lag-response functions, respectively.

Risk ratios (RR) of hospital admissions and deaths were calculated for a $10 \mu \mathrm{g} / \mathrm{m}^{3}$ increase in air pollutant concentrations. Reported estimates, computed as the risk at day 0 (day of high measured pollution levels), and the cumulative risk over the total lag period, are presented with corresponding $95 \%$ confidence intervals (CI).

In a next set of $\mathrm{DL}(\mathrm{N}) \mathrm{M}$ models, air pollution exposures were categorized into quartiles, and RRs of ALI admissions for high pollution days (fourth quartile) versus low pollution days (first quartile) were estimated. As there was little difference between pollution levels in Dundee and Perth, quartiles were calculated by using combined pollution data.

Potential reduction in ALI admissions were calculated, using mean total admissions. These estimates were used to calculate the potential reduction in ALI admissions for a reduction in air pollution concentrations from the fourth to the first quartile. The reduction was calculated relative to the mean number of admissions over the study period. Due to the small numbers of ALI related deaths during the study period ( $\mathrm{n}=1003$ deaths with ALI recorded as primary cause of death), potential reduction of deaths associated with pollution reduction were not calculated. All analyses were performed with the statistical software $\mathrm{R}$ ( $\mathrm{R}$ Foundation for Statistical Computing, Vienna, Austria) using the "dlnm" package (https://cran.r-project.org/web/packages/dlnm/index.html).

\section{Results}

Over the 18-year study period, out of 5,608 admissions to hospital 2,697 people had a primary admission reasons of ALI, as defined in the methods. Of these, 4,280 admissions in 2,032 people were within Dundee, and 1,328 admissions in 665 people were from Perth. For the ICD10 codes of I702, I739 and I74, there was a total of 28, 2460 and 318 patients admitted to hospital over the study period, respectively (with 112 of these being admitted for more than one code). This accounted for 33, 5,181 and 394 admissions respectively. The average age of patients admitted for ALI was 71.2 years ( $S D=11.1 \mathrm{yrs}$ ). There were 1003 deaths where the primary cause of death was registered as ALI over the study period.

Pollutant levels of the study area and split for city are displayed in Table I. Quartiles were defined using joint data for Dundee and Perth.

\section{ALI hospital admissions}

Figure 1 shows lag-specific RRs for ALI hospitalization associated with a $10 \mu \mathrm{g} / \mathrm{m}^{3}$ increase in air pollution concentrations. Increased ALI hospitalization was observed on the day (lag 0) and the day after (lag 1) the exposure for all pollutants. Same-day (lag 0) RRs for a $10 \mu \mathrm{g} / \mathrm{m}^{3}$ increase in air pollutant concentrations were significant for $\mathrm{NO}_{\mathrm{x}}(1.006$; 95\% CI 1.001-1.011)) and NO (1.012; 95\% CI 1.0021.022), but not for $\mathrm{NO}_{2}$ (1.020; 95\% CI 0.998-1.042)) and PM10 (1.018; 95\% CI 0.991-1.046) (Table II). Corresponding cumulative (lag 0-9) estimates did not reach significance for any of the pollutants. RRs for high (fourth quartile) versus low (first quartile) air pollution concentrations on the day of exposure (lag 0 ) were statistically significant for all four pollutants: 1.185 (95\% CI 1.072-1.309), 1.098 (95\% CI 1.000-1.206), 1.203 (95\% CI 1.089-1.330) and 1.068 (95\% CI 0.990-1.152), for $\mathrm{NO}_{\mathrm{x}}, \mathrm{NO}_{2}$, $\mathrm{NO}$ and PM10, respectively. Although day of high pollution did not produce significant results for PM10, corresponding cumulative (lag 0-9) estimate was significant for PM10 $(\mathrm{RR}=1.283 ; 95 \% \mathrm{CI} 1.028-1.601)$, though the lag phase data were not significant for the others.

\section{Reduction in ALI hospital admissions}

There was an average of 320.5 ALI hospital admissions per year over the study period. If pollution levels were kept within the quartile 1 level of pollution for $\mathrm{NO}_{\mathrm{x}}, \mathrm{NO}_{2}, \mathrm{NO}$ and PM10, we calculated that this would result in a potential 19-32\% reduction in ALI admissions (Table III).

\section{Mortality data}

There was no association between any of the pollutants, $\mathrm{NO}_{\mathrm{x}}, \mathrm{NO}_{2}, \mathrm{NO}$ and PM1O and an increased risk of ALI deaths during the study period, when assessing pollution as $10 \mu \mathrm{g} / \mathrm{m}^{3}$ increments or as quartiles (ESM 5).

\section{Discussion}

This study assessed the relationship between $\mathrm{NO}_{\mathrm{x}}, \mathrm{NO}_{2}$, NO and PM10, air pollution on ALI hospital admissions and deaths, in Tayside, Scotland. We report the novel finding in ALI that $\mathrm{NO}_{\mathrm{x}}$ and $\mathrm{NO}$ were significantly associated 


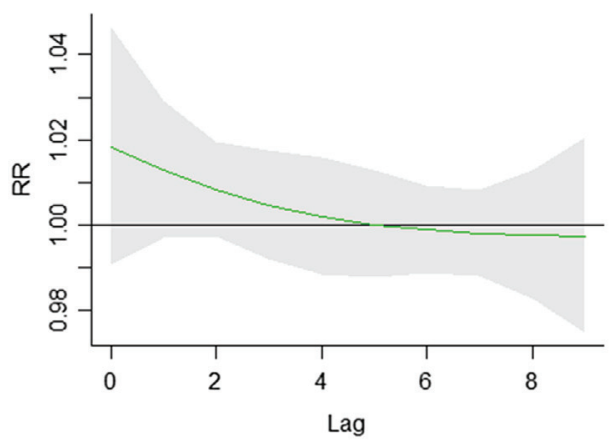

Association with a 10-unit increase in NO2

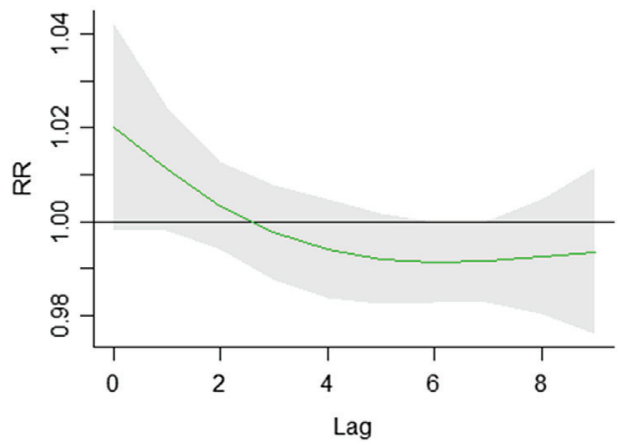

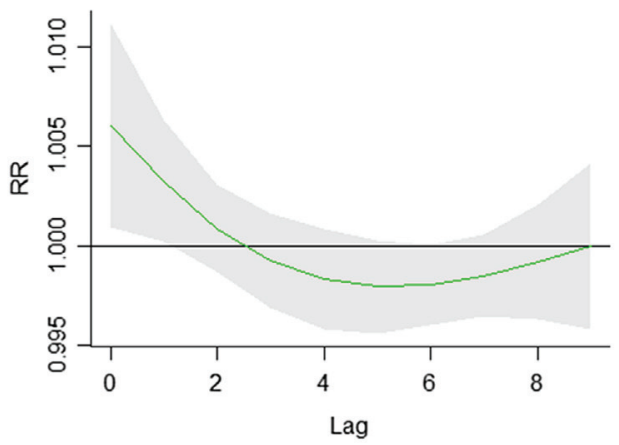

Association with a 10-unit increase in NO

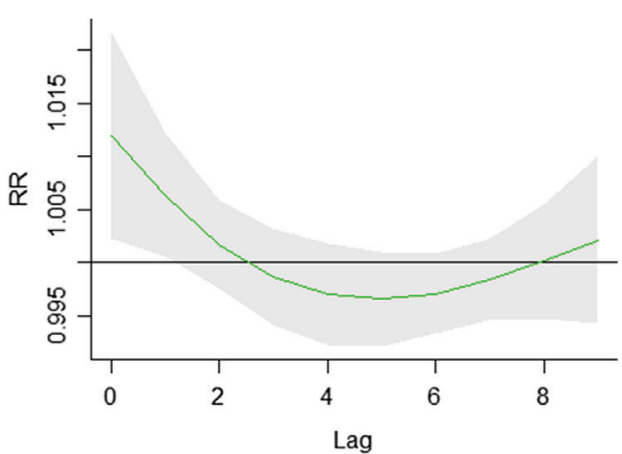

Figure 1. Slice diagrams demonstrating the risk ratio trend for acute limb ischaemia (ALI) hospital admissions over the lag period (0-9 days) for a $10 \mu \mathrm{g} / \mathrm{m}^{3}$ increase in particulate matter with a diameter smaller than $10 \mu \mathrm{m}$ (PM10), nitrogen oxides ( $\left.\mathrm{NO}_{x}\right)$, nitric oxide $\left(\mathrm{NO}_{2}\right)$, nitrous oxide ( $\left.\mathrm{NO}\right)$.

Table II. Adjusted risk ratios with $95 \%$ confidence intervals at day 0 and cumulative risks (0-9 days) for Acute Limb Ischaemia hospital admissions and exposure to $10 \mu \mathrm{g} / \mathrm{m}^{3}$ increase in pollutants and quartile 4 vs quartile 1

\begin{tabular}{|c|c|c|c|c|}
\hline & \multicolumn{2}{|c|}{$10 \mu \mathrm{g} / \mathrm{m}^{3}$} & \multicolumn{2}{|c|}{ Q4 vs Q1 } \\
\hline & $\mathrm{RR}(95 \% \mathrm{Cl})$ & $P$ value & RR $(95 \% \mathrm{Cl})$ & $P$ value \\
\hline \multicolumn{5}{|l|}{ Day 0} \\
\hline PM10 & $1.018(0.991-1.046)$ & 0.197 & $1.068(0.990-1.152)$ & 0.089 \\
\hline $\mathrm{NO}_{x}$ & $1.006(1.001-1.011)$ & 0.018 & $1.185(1.072-1.309)$ & 0.001 \\
\hline $\mathrm{NO}_{2}$ & $1.020(0.998-1.042)$ & 0.072 & $1.098(1.000-1.206)$ & 0.050 \\
\hline NO & $1.012(1.002-1.022)$ & 0.018 & $1.203(1.089-1.330)$ & $<0.001$ \\
\hline \multicolumn{5}{|c|}{ Cumulative } \\
\hline PM10 & $1.039(0.965-1.119)$ & 0.316 & $1.283(1.028-1.601)$ & 0.027 \\
\hline $\mathrm{NO}_{x}$ & $1.001(0.986-1.017)$ & 0.907 & $1.148(0.837-1.576)$ & 0.400 \\
\hline $\mathrm{NO}_{2}$ & $0.986(0.924-1.053)$ & 0.685 & $1.003(0.747-1.346)$ & 0.986 \\
\hline NO & $1.010(0.982-1.039)$ & 0.499 & $1.138(0.832-1.529)$ & 0.412 \\
\hline
\end{tabular}

Models adjusted for day of week, month, public holiday, daily temperature and humidity. $\mathrm{NO}_{\mathrm{x}}$ : nitrogen oxides; $\mathrm{NO}_{2}$ : nitric oxide; $\mathrm{NO}$ : nitrous oxide; PM10: particulate matter with a diameter smaller than $10 \mu \mathrm{m}$.

with an increase of ALI hospital admissions on the day of exposure, with evidence of an effect throughout the lag period, which reached significance for PM10. There was no association between ALI deaths and high pollution levels.

There is some early work on air pollution and development of peripheral arterial disease in general [20, 21, 22] but no-one has evaluated the effect on ALI. Our study therefore adds a novel finding to the limited knowledge regarding the adverse effects of $\mathrm{NO}_{\mathrm{x}}$ and $\mathrm{NO}$ air pollution, which is increasing Acute Limb Ischaemia events on high pollution days. As $\mathrm{NO}_{\mathrm{x}}$ is a majority mixture of $\mathrm{NO}, \mathrm{NO}_{2}$ with other particulates, it is likely that the increased risk for $\mathrm{NO}_{\mathrm{x}}$ is driven by the NO proportion in our study. We know that these gases, when inhaled, reach the blood stream where they have a noxious effect by directly damaging endothelium, increasing blood pressure and increasing the oxidation of LDL [23] and it is therefore unsurprising to see an immediate effect on the day of high gas levels.

PM10 pollution is arguably the most researched constituent of air pollution and has previously been linked with various adverse cardiovascular outcomes [24]. Exposure to 
Table III. Potential reduction of acute limb ischaemia hospital admissions per year for each pollutant, if all days were within Q1 limits. Based on admission data from 2016/2017 in Dundee - based on a mean total admins/yr of 320.5

\begin{tabular}{lccc}
\hline Pollutant & $\begin{array}{c}\text { Mean reduction } \\
\text { in admins/day }\end{array}$ & $\begin{array}{c}\text { Mean total } \\
\text { reduction/yr }\end{array}$ & \% Reduction \\
\hline $\mathrm{NO}_{2}$ & 0.23 & 83.14 & 25.9 \\
$\mathrm{NO}$ & 0.29 & 105.57 & 32.9 \\
$\mathrm{NO}_{x}$ & 0.29 & 104.36 & 32.6 \\
$\mathrm{PM10}$ & 0.17 & 61.90 & 19.3 \\
\hline
\end{tabular}

$\mathrm{NO}_{\mathrm{x}}$ : nitrogen oxides; $\mathrm{NO}_{2}$ : nitric oxide; $\mathrm{NO}$ : nitrous oxide; PM10: particulate matter with a diameter smaller than $10 \mu \mathrm{m}$.

PM10 has been postulated to produce systemic inflammation, thrombotic reaction, and autonomic nervous system imbalance $[25,26,27]$. There is a large body of literature of how air pollution affects arteries, although most experimental work has been done on peripheral arteries, the papers use these experiments to extrapolate to coronary vessels and may also explain ALI. We report a significant association between the ALI hospitalisation and the cumulative effects of PM10. PM10 particles induce an inflammatory repose over time. Exposure to PM 10 is associated with elevated systemic levels of C-reactive protein (CRP), elevated blood viscosity and thrombus formation [28].

We also calculated that if pollutant levels were reduced to quartile 1 levels there is a potential to reduce ALI hospital admissions by $30 \%$. However, we cannot say what the association is between each pollutant type.

\section{Limitations}

Some limitations of the study should be addressed: firstly, the study design does not take into account individual person factors (previous cardiovascular disease, smoking, diabetes), which may be associated with ALI admissions, or extent of exposure, although we did exclude the ICD10 codes for ALI secondary to diabetes which would have excluded all patients with known diabetes at the time of admission. It is unlikely that chronic risk factors are associated with short-term fluctuations in air pollution levels, however future welldesigned cohort studies taking into account key risk factors and comorbidities would be helpful to confirm the findings in this study.

Secondly, it is recognised that air pollution can promote arrythmia [29] and arrythmia is a common cause of ALI, when an embolus is thrown off from a fibrillating heart. We are unable to determine if this was the case, as we had no access to ECGs. If embolus were the cause this would make the ALI a secondary effect of the pollution, albeit a most serious one.

We also used single monitoring stations in Dundee and Perth to estimate personal exposure to air pollution, which may result in magnitude of effects on exposures to air pollution obtained from regression modelling to be smaller than the actual impact, due to non-systematic exposure misclassification [30]. Furthermore, as the pollutants are modelled separately, we cannot say whether they provide an additive effect. $\mathrm{NO}_{\mathrm{x}}, \mathrm{NO}_{2}$ and $\mathrm{NO}$ are likely to be highly correlated. In addition to these limitations, ambient air pollution may not translate directly to population exposure.

Another limitation of this study is there is no way to determine whether use of ICD10 codes used to identify hospital admissions is consistent between hospitals or over time.

There has been a focus on improving air quality in the UK for the past 20 years, which has largely centred on the reduction of PM10 pollution. However, more needs to be done in Tayside, and elsewhere, where these results might be extrapolated, to address the high $\mathrm{NO}_{\mathrm{x}}$ and $\mathrm{NO}$ pollution levels, particularly considering the increased risks reported here, and in other studies [11, 12, 13, 14, 15, 26].

\section{Conclusions}

We report for the first time a significant increase of acute limb ischaemia hospital admissions following high measured pollution levels of $\mathrm{NO}_{\mathrm{x}}$, NO and PM10 air pollution on day of exposure. If air pollution were kept to low levels, acute limb ischaemia hospital admissions in Tayside could be potentially reduced by $30 \%$.

\section{Electronic supplementary material}

The electronic supplementary material (ESM) is available with the online version of the article at https://doi.org/ 10.1024/0301-1526/a000972

ESM 1. Table of ICD10 codes used over the study period and descriptions. ICD10 codes did not change through the updated versions of ICD10, and so these codes are valid for each reiteration (2000-2106) (Table)

ESM 2. Map of Scotland districts. Dundee city, Perth city, Milnfield and Leuchars stations are marked (Figure)

ESM 3. Dundee postcode districts, with city centre marked. DD1, DD2, DD3, DD4, DD5, DD6 and DD7 were used in this study (Figure)

ESM 4. Perth postcode districts with city centre marked. PH1 and PH2 used for this study (Figure)

ESM 5. Adjusted risk ratios with $95 \%$ confidence intervals at day 0 and cumulative risks (0-9 days) for acute limb ischemia deaths and exposure to $10 \mu \mathrm{g} / \mathrm{m}^{3}$ increase in pollutants, and quartile 4 vs quartile 1 (Table)

\section{References}

1. World Health Organization. Air Quality Guidelines Global Update 2005. Particulate matter, ozone, nitrogen dioxide and sulfur dioxide. Geneva: WHO; 2005. Available from: https:// www.euro.who.int/__data/assets/pdf_file/0005/78638/ E90038.pdf 
2. Carvalho H. Air pollution-related deaths in Europe - time for action. J Glob Health. 2019;9:020308.

3. Manisalidis I, Stavropoulou E, Stavropoulos A, Bezirtzoglou E. Environmental and health impacts of air pollution: A review. Front Public Health. 2020;8:14.

4. Landrigan PJ, Fuller R, Acosta NJR, Adeyi O, Arnold R, Basu NN, et al. The Lancet Commission on pollution and health. Lancet. 2018;391:462-512.

5. Obara H, Matsubara K, Kitagawa Y. Acute limb ischemia. Ann Vasc Dis. 2018;11:443-8.

6. Frank U, Nikol S, Belch JJF, Boc V, Brodmann M, Carpentier $\mathrm{PH}$, et al. ESVM guideline on peripheral arterial disease. VASA. 2019;48:1-79.

7. Howard DP, Banerjee A, Fairhead JF, Hands L, Silver LE, Rothwell PM, et al. Population-based study of incidence, risk factors, outcome, and prognosis of ischemic peripheral arterial events: implications for prevention. Circulation. 2015;132: 1805-15.

8. Chung J, Bang OY, Ahn K, Park S, Park TH, Kim JG, et al. Air pollution is associated with ischemic stroke via cardiogenic embolism. Stroke. 2017;48:17-23.

9. Hoek G, Brunekreef B, Fischer P, van Wijnen J. The association between air pollution and heart failure, arrhythmia, embolism, thrombosis, and other cardiovascular causes of death in a time series study. Epidemiology. 2001;12:355-7.

10. Chen S, Chan C, Ta Su. Particulate and gaseous pollutants on inflammation, thrombosis, and autonomic imbalance in subjects at risk for cardiovascular disease. Environ Pollut. 2017;223:403-8.

11. Rückerl R, Hampel R, Breitner S, Cyrys J, Kraus U, Carter J, et al. Associations between ambient air pollution and blood markers of inflammation and coagulation/fibrinolysis in susceptible populations. Environ Int. 2014;70:32-49.

12. Donaldson K, MacNee W. Potential mechanisms of adverse pulmonary and cardiovascular effects of particulate air pollution. Int J Hyg Environ Health. 2001;203:411-5.

13. Hampel R, Peters A, Beelen R, Brunekreef B, Cyrys J, de Faire $U$, et al. Longterm effects of elemental composition of particulate matter on inflammatory blood markers in European cohorts. Environ Int. 2015;82:76-84.

14. Viehmann A, Hertel S, Fuks K, Eisele L, Moebus S, Möhlenkamp S, et al. Long-term residential exposure to urban air pollution, and repeated measures of systemic blood markers of inflammation and coagulation. Occup Environ Med. 2015;72:656-63.

15. Mills NL, Törnqvist H, Robinson SD, Gonzalez M, Darnley K, MacNee W, et al. Diesel exhaust inhalation causes vascular dysfunction and impaired endogenous fibrinolysis. Circulation. 2005;112:3930-6.

16. Gasparrini A, Armstrong B, Kenward MG. Distributed lag nonlinear models. Stat Med. 2010;29(21):2224-34.

17. Armstrong B. Models for the relationship between ambient temperature and daily mortality. Epidemiology. 2006;17:624-31.

18. Gasparrini A. Distributed lag linear and non-linear models in R: The package dlnm. J Stat Softw. 2011;43:1-20.

19. Law $Y$, Chan YC, Cheng SWK. Impact of ambient temperature on incidence of acute lower limb ischemia. Ann Vasc Surg. 2017:44:393-9

20. Ward-Caviness CK, Kraus WE, Blach C, Haynes CS, Dowdy E, Lynn Miranda M, et al. Associations between residential proximity to traffic and vascular disease in a cardiac catheterization Cohort. Arterioscl Throm Vas. 2018;38:275-82.

21. Hoffmann B, Moebus S, Kröger K, Stang A, Möhlenkamp S, Dragano N, et al. Residential exposure to urban air pollution, ankle-brachial index, and peripheral arterial disease. Epidemiol. 2009;20:280-8.

22. Kloog I. Fine particulate matter (PM2.5) association with peripheral artery disease admissions in northeastern United States. Int J Environ Health Res. 2016;26:572-7.

23. Münzel T, Gori T, Al-Kindi S, Deanfield J, Lelieveld J, Daiber A, et al. Effects of gaseous and solid constituents of air pollution on endothelial function. Euro Heart J. 2018;39:3543-50.

24. Brook RD, Rajagopalan S, Pope CA 3rd, Brook JR, Bhatnagar A, Diez-Roux AV, et al. Particulate matter air pollution and cardiovascular disease: An update to the scientific statement from the American Heart Association. Circulation. 2010;121: 2331-78.

25. Franchini M, Mannucci PM. Thrombogenicity and cardiovascular effects of ambient air pollution. Blood. 2011;118:2405-12.

26. Franchini M, Guifa A, Tufano A, Coppola A. Air pollution, vascular disease and thrombosis: linking clinical data and pathogenic mechanisms. J Thromb Haemost. 2012;10:2438-51.

27. Nelin TD, Joseph AM, Gorr MW, Wold LE. Direct and indirect effects of particulate matter on the cardiovascular system. Toxicol Lett. 2012;208:293-9.

28. Pope CA, Burnett RT, Thurston GD, Thun MJ, Calle EE, Krewski D, et al. Cardiovascular mortality and long-term exposure to particulate air pollution: Epidemiological evidence of general pathophysiological pathways of disease. Circulation. 2004;109:71-7.

29. Shahrbaf MA, Akbarzadeh MA, Tabary M, Khaheshi I. Air pollution and cardiac arrhythmias: A comprehensive review. Curr Prob Cardiology. 2021;46:100649.

30. Zeger SL, Thomas D, Dominici F, Samet JM, Schwartz J, Dockery D, et al. Exposure measurement error in time-series studies of air pollution: Concepts and consequences. Environ Health Perspect. 2000;108:419-26.

\section{History}

Submitted: 09.04.2021

Accepted after revision: 17.08.2021

Published online: 08.11.2021

\section{Acknowledgements}

This study was funded by the Miller Bequest and the Institute for Cardiovascular Research charity. We should also like to acknowledge the safe haven, The Health Informatics Centre, University of Dundee, who provided the linkage data.

\section{Conflict of interest}

The authors declare that there are no conflicts of interest.

\section{Author contributions}

JJFB had the original concept. CAF, BC, JC, JJFB agreed on the project design. CAF undertook the analysis, CAF, BC, JC, JJFB interpreted the results. CAF drafted the manuscript and CAF, BC, JC, JJFB made changes and agreed on the final manuscript.

\section{Correspondence address}

Prof. Jill J. F. Belch

University of Dundee

Ninewells Hospital and Medical School

Dundee DD1 9SY

UK

j.j.f.belch@dundee.ac.uk 